\title{
O papel subestimado do interlocutor na abordagem cognitiva da metáfora
}

\author{
Ulrike Schröder *
}

\begin{abstract}
Resumo
Uma das maiores críticas voltadas para a Teoria da Metáfora Conceitual é que Lakoff e Johnson $(2003,1999)$ partem de uma constelação idealizada de interlocutores, de modo que o processo da compreensão de uma metáfora simplesmente se dá por meio da ativação de metáforas conceptuais, entrincheiradas no cérebro dos participantes (GIBBS, 2007). Procurar-se-á investigar quais as abordagens que dirigem sua atenção ao ouvinte como parte ativa por coconstruir o significado particular da expressão metafórica em dependência do contexto pragmático, social e cultural em que os interlocutores estão inseridos. A questão central é até que ponto os estudos existentes conseguem reintegrar o processo holístico da comunicação, e, para tal, distinguimos entre três linhas de pesquisa a serem aprofundadas: estudos psicolinguísticos, textual-discursivos e pragmático-interacionais.

Palavras-chave: Teoria da Metáfora Conceitual. Interlocutor. Compreensão. Comunicação. Interação.
\end{abstract}

\section{Introdução}

Junto à publicação do livro Metaphors we live by (LAKOFF; JOHNSON, 2003), ${ }^{1}$ surgiu a Semântica Cognitiva como nova linha de pesquisa, que até hoje não perdeu sua popularidade. Muito pelo contrário, observa-se, por um lado, um crescimento do interesse interdisciplinar na Teoria da Metáfora Conceitual e, por outro lado, um aumento de estudos empíricos em busca de evidências que tornem as bases da teoria mais sólidas. Contudo, apesar das exaltações, há uma série de críticas reivindicando uma mudança paradigmática acerca do foco representacional da teoria, uma mudança tal que tirasse as expressões metafóricas do seu contexto comunicativo-funcional, reduzindo, destarte, o fenômeno da metáfora a princípios cognitivos pré-linguísticos. ${ }^{2}$

* Universidade Federal de Minas Gerais - UFMG.

1 Convém salientar que Lakoff e Johnson não inventaram a teoria. De fato, há um número indefinido de antecipações no campo da filosofia, psicologia e linguística (cf. SCHRÖDER, 2012).

2 Cf. Schröder (2011). 
Sendo assim, coloca-se a questão de qual seria o papel da metáfora na estrutura específica da interação comunicativa, estabelecida pelas coordenações recíprocas dos interlocutores, que interagem com base na força persuasiva da língua. Nas antecipações da teoria cognitiva da metáfora, tais questões já foram aprofundadas, especialmente na linha de pensamento de Philipp Wegener (1991), Karl Bühler (1982), Gerold Ungeheuer $(2004,1987)$ e Heinrich Walter Schmitz $(1998,2003)$. Convém relembrar alguns postulados desses autores.

O estudo da comunicação é visto como a busca pelas condições estruturais e funcionais da interação como coordenadoras recíprocas da ação, mediada simbolicamente. Por conseguinte, o foco está no uso situativo dos meios verbais, paraverbais e não verbais, em vez de uma abordagem que descreva a língua exclusivamente como ferramenta pré-dada. Ressaltando a diferença entre essas duas visões, Ungeheuer (2004) introduz, por um lado, a distinção entre 'perspectiva comunicativa' e 'extracomunicativa' com base na filosofia fenomenológica, recorrendo à distinção de 'Zuhandenem' (estar à disposição) e 'Vorhandenem' (ser existente) de Heidegger (1957) e à diferença entre 'fungierend' (funcionando) e 'thematisierend' (tematizando) de Husserl (1921, p. 261-265). Por outro lado, Ungeheuer segue a abordagem linguística de Karl Bühler, que separa entre teorias da língua como ato e como formação, as quais são fundamento para uma perspectiva funcionalista do falar, ligada ao sujeito, e uma perspectiva do objeto, desligada do sujeito. (BÜHLER, 1982, p. 48-69) Ora, em perspectiva comunicativa, a unidade entre falante e ouvinte na sua ação coorientada é de uma importância imprescritível para qualquer tipo de análise. Tal ângulo rejeita uma divisão do "evento comunicativo em eventos parciais, quase autônomos no lado do falante e do ouvinte" (SCHMITZ, 1998, p. 318), ${ }^{3}$ como a posição que se encontra no modelo tradicional da transposição ou na teoria dos atos de fala. (SCHMITZ, 2003, p. 200-201). É esse papel do interlocutor, até hoje ainda marginal, que queremos tematizar a seguir. Pergunta-se até que ponto as críticas voltadas para a falta de uma contextualização interacional da metáfora conceitual, no decorrer dos últimos anos, já desenvolveram abordagens na direção de uma reintegração do interlocutor, tirando-o da sua passividade e tornando-o um construtor ativo do significado metafórico.

3 "Kommunikationsgeschehens in quasi-autonome Teilgeschehen auf Sprecher- und Hörerseite". 


\section{Abordagens no campo da psicolinguística}

O interesse no ouvinte surge em pesquisas do campo da psicolinguística que buscam por evidências empíricas da interação entre os níveis linguístico e cognitivo. Gibbs debruça-se sobre as vaguezas da Teoria Conceitual da Metáfora e formula quatro hipóteses a serem testadas em estudos empíricos distintos.

1. Metáforas conceituais motivam o significado em perspectiva histórica, mas não têm mais papel na interação concreta.

2. Metáforas conceituais motivam o significado de expressões metafóricas, embora não façam parte do sistema conceitual dos interlocutores.

3. Metáforas conceituais motivam o significado de expressões metafóricas e fazem parte do sistema conceitual dos interlocutores, embora não sejam mais ativadas no uso atual.

4. Metáforas conceituais motivam o significado das expressões ainda ativamente assim que um interlocutor usar e entender metáforas na fala. (GIBBS, 2007, p. 46-47)

Um dos primeiros estudos (GIBBS; O’BRIAN, 1990) pergunta pelas imagens mentais construídas por ouvintes quando ouvem expressões idiomáticas como spill the beans ('revelar um segredo'). O resultado revelou que a maioria dos participantes tinha imagens semelhantes: os feijões ficavam em uma tigela do tamanho de uma cabeça, foram vertidos por engano e cobriram o chão depois. Referindo-se a essas paralelas nas descrições do cenário, os autores concluem que metáforas conceituais assumem um papel-chave na motivação dos significados de expressões idiomáticas. Porém, pode-se acrescentar a pergunta não esclarecida de como tais imagens entram no estoque de conhecimento das pessoas e qual o papel da cultura delas.

Em outro experimento, os participantes receberam o seguinte texto:

Mary was very tense about this evening's dinner party. The fact that Bob had not come home to help was making her fume. She was getting hotter with every passing minute. Dinner would not be ready before guests arrived. As it got closer to five o'clock the pressure was really building up. Mary's tolerance was reaching its limits. When Bob strolled in at ten minutes to five whistling and 
smiling, Mary

(1) blew her stack

(2) bit his head off

(NAYAK; GIBBS, 1990)

Os participantes tiveram que escolher qual das duas expressões se inseria melhor no contexto, e a maioria escolheu a primeira, resultado em concordância com o domínio-fonte já introduzido pelas expressões precedentes fume, hotter, pressure, reaching its limits. A primeira expressão é ativada pela metáfora conceitual ANGER IS HEAT IN A PRESSURIZED CONTAINER, ao passo que a escolha da segunda expressão resultaria em uma ruptura com a alegoria no contexto dado. Portanto, quando um segundo grupo teve que escolher entre as duas expressões com base no mesmo texto, no qual apenas foram substituídas aquelas expressões pelas palavras grouchy, growling under her breath e savage, o grupo optou pela segunda variante, por sua afinidade com a metáfora superior ANGRY BEHAVIOR IS ANIMAL BEHAVIOR. Sendo assim, como os participantes tenderam a uma congruência entre a informação linguística e contextual, segundo Gibbs, a terceira hipótese foi afirmada. (GIBBS, 2007, p. 50)

Wilson e Gibbs (2007) dedicam-se à correlação entre atividades corporais e processos de compreensão metafórica para testar a hipótese do embodiment. ${ }^{4} \mathrm{~A}$ pergunta estabelecida foi se os participantes entenderiam frases metafóricas como grasp the concept mais rapidamente se tivessem realizado a atividade corporal 'pegar algo' anteriormente. O resultado dá apoio empírico à quarta hipótese de Gibbs: "engaging in body movements associated with these phrases should enhance the simulations that people create to form a metaphorical understanding of abstract notions". (GIBBS, 2007, p. 53). Uma vez que houve dois experimentos - um no qual os próprios participantes realizaram o movimento, e outro no qual a atividade somente foi mostrada numa tela - sem que tenha havido diferenças no resultado, conclui-se que a hipótese do enactment parece plausível, pois não faz nenhuma diferença se a ação é realizada ou simulada mentalmente.

4 A Hipótese do Realismo Corporificado (embodiment) localiza a capacidade epistemológica do ser humano nas suas interações corporais com seu meio. Com este ponto de vista, a Semântica Cognitiva se distingue de posições filosóficas e linguísticas da lógica formal como também testemunha o título do livro Philosophy in the Flesh. The Embodied Mind and its Challenge to Western Thought (LAKOFF; JOHNSON, 1999) na qual os autores até falam de um phenomenological embodiment (LAKOFF; JOHNSON, 1999, p. 36), referindo-se às teorias de Merleau-Ponty e Dewey. 
Outra metodologia para se aproximar do processo da compreensão de metáforas é o procedimento do Goal-directed Interactive Think Aloud (GITA), no qual um grupo lê um texto negociando, concomitantemente, os significados, isto é, busca-se captar as atitudes comunicativas e extracomunicativas entre as quais os participantes oscilam reciprocamente durante o processo da compreensão. Zanotto e Palma (2008) realizaram tal experimento com alunos que tiveram que definir o significado da expressão foicinha em um poema de Carlos Drummond de Andrade. Ora, revelaram-se interpretações distintas com relação à questão de se tratar de uma metáfora ou de uma metonímia, o que mostra que, na perspectiva comunicativa em vez de uma perspectiva extracomunicativa, desligada da situação, o fenômeno da metáfora apresenta "a more complex matter, a polysemous amalgam of metaphors and metonymies" (ZANOTTO; PALMA, 2008, p. 37), pois o significado não preexiste, mas é construído pelo interlocutor em sintonia com estratégias distintas como substituição, incongruência e a integração de indicadores dêicticos, textuais, contextuais e fatores culturais.

Para melhor analisar o processamento da metáfora, há estudos que realizam testes medindo o tempo de reação que leitores de expressões metafóricas necessitam (HOFFMAN; KEMPER, 1987) ou os movimentos dos olhos junto às atividades cerebrais (GIORA, 2003). Gibbs conclui que, em dependência do tempo corrido, há quatro formas de processamento metafórico interligadas à respectiva intensidade do processo da compreensão:

1. Comprehension: A compreensão refere-se ao processo atual e imediato da construção do significado perante o contexto e o conhecimento do mundo do interlocutor.

2. Recognition: $\mathrm{O}$ reconhecimento refere-se à identificação consciente e reflexiva da metáfora como type, processo que, por sua velocidade, está mais presente na leitura do que na fala.

3. Interpretation: A interpretação refere-se à análise de construções precedentes da compreensão como tokens. Uma crítica literária pode interpretar um texto como tendo um tópico alegórico prototípico em atitude reflexiva.

4. Appreciation: O julgamento refere-se ao aspecto estético com relação a um type ou token. (GIBBS, 1994, p. 116-117)

Apenas o primeiro processo é obrigatório. Na terminologia de Ungeheuer, os passos 2 a 4 marcariam uma atitude extracomunicativa, aquilo que Gibbs chama atitude 'consciente' ou 'reflexiva'. 


\section{Abordagens no campo da linguística textual e discursiva}

Seguindo o modelo de uma graduação do processo da compreensão, na sua obra Understanding metaphor in literature, Gerard Steen (1994) distingue entre níveis diferentes do processamento metafórico no discurso, considerando a divisão entre o sistema da língua e o seu uso. De acordo com essa distinção, metáforas podem (a) não ter mais relevância nenhuma no processo online dos interlocutores em uma interação atual, quando se trata, por exemplo, de uma simples desambiguização de polissemia motivada historicamente, (b) tornar-se ativas, quando se trata de uma atualização de mapeamentos metafóricos entrincheirados ou (c) ter relevância máxima, de tal forma que o mapeamento metafórico somente é construído pelos interlocutores no caso de metáforas desconhecidas e inovativas. Steen procede de modo experimental, pedindo a alguns voluntários que comentassem durante sua leitura se e como eles entendem uma expressão metafórica. Posteriormente, Steen estabelece dez tipos de estratégias utilizadas:

1. Problem recognition: O leitor exprime dificuldades e dúvidas com relação a uma expressão metafórica dada.

2. Metaphor recognition: $\mathrm{O}$ leitor articula metalinguisticamente sua compreensão.

3. Labeling: O leitor interliga os domínios-fonte e alvo explicitamente através de uma partícula.

4. Focus processing: O leitor processa a metáfora exclusivamente pelo domínio-alvo.

5. Vehicle processing: O leitor processa a metáfora exclusivamente pelo domínio-fonte.

6. Metaphor construction: $\mathrm{O}$ leitor interpreta a metáfora na interação entre domínio-fonte e alvo.

7. Metaphor functionalization: O leitor interliga a metáfora com outras partes do texto ou suas próprias interpretações precedentes.

8. Metaphor context construction: O leitor interliga a metáfora com a intenção do autor.

9. Metaphor refunctionalization: O leitor interliga a metáfora com outras metáforas já interpretadas.

10. Metaphor appreciation: O leitor enuncia sua opinião quanto à classificação ou qualidade da metáfora. (STEEN, 1994, p. 137) 
Essa classificação já nos revela que Steen localiza o processamento metafórico primeiramente no seu meio cotextual e contextual. Adicionalmente, acerca dos gêneros textuais 'literatura' e 'artigo jornalístico', Steen chega à conclusão de que as atitudes perante a questão de o que etiquetar como 'metafórico' mudam em dependência do status educacional e profissional. Sendo assim, expertos literários, por exemplo, processam metáforas mais conscientemente do que outras pessoas. Mais tarde, Steen (2004) retoma a questão das características do texto que influenciam a identificação de metáforas e descobre que metáforas explícitas com uma estrutura ' $\mathrm{X}$ é [metáfora]' são mais transparentes para leitores do que metáforas implícitas. Concomitantemente, revelou-se que metáforas nominais são mais facilmente reconhecidas do que metáforas verbais, o que Steen explica a partir do contorno concreto, reificado e esquemático que substantivos possuem em oposição a verbos. Finalmente, outro ponto decisivo é a posição da metáfora no texto. Os voluntários reconheceram metáforas pós-verbais com mais facilidade do que pré-verbais, o que, segundo Steen, acontece devido à sequência tema/rema, uma vez que a segunda posição do rema guia a atenção do leitor. Pelo mesmo motivo, o leitor tem mais facilidade em identificar uma metáfora quanto mais ele tiver progredido no texto, uma vez que o mundo textual se torna cada vez mais delimitado. Destarte, como sugere Steen, textualidade determina de modo incisivo a percepção e identificação de uma metáfora por um leitor ou ouvinte (STEEN, 2007, p. 94-97). No que tange à abordagem cognitiva da metáfora, Steen defende uma nova orientação voltada para o interlocutor e seu processamento no contexto da interação em questão:

The behavioral study of metaphor in usage events can therefore not remain restricted to the sentence processing paradigms that are popular in psycholinguistics. It also requires attending to the definition of the usage event as a purposeful form of verbal action or communication, or discourse, to the participants. People use language on particular occasions in specific roles, for particular goals, about particular topics, in particular settings, and against the background of specific norms and expectations. (STEEN, 2007, p. 352-353).

Steen recorda os trabalhos no campo da Sociolinguística Interacional e da Etnografia da Comunicação, reivindicando uma ponte entre as duas linhas de 
pesquisa para superar a artificialidade dos estudos psicolinguísticos situados em laboratórios, ao invés de contextos discursivos reais. Embora a contribuição de Steen seja de importância fundamental para tal direção, é ele mesmo quem muitas vezes continua preso a uma terminologia emprestada da semântica formal, que busca superar. Ele até usa termos como sender e receiver (STEEN, 2004, p. 1297), que lembram os modelos transpositivos das teorias informacionais.

Como Steen, no caso da distinção entre expertos e leigos, Lynne Cameron (1999, p. 108) destaca a importância da questão para quem a instância linguística apresenta uma metáfora, diferenciando entre process metaphors e linguistic metaphors (CAMERON, 1999, p. 108): no primeiro caso, trata-se de metáforas na perspectiva dos participantes, utilizadas em uma ação específica. No segundo caso, trata-se de metáforas classificadas teoricamente por um observador externo. Aqui, Cameron introduz sua própria terminologia para apontar a diferença entre as perspectivas comunicativa e extracomunicativa. Semelhante a Ungeheuer, Cameron lamenta que a metáfora processual, nas abordagens científicas, até hoje em dia, não receba a atenção que merece. Como caso prototípico, ela aponta crianças que ainda recorrem ao domínio-fonte para entender expressões metatóricas que adultos já interpretam automaticamente como pertencentes ao domínio-alvo. Para ilustração, ela descreve uma situação na qual uma criança interpreta a expressão hot spells (onda de calor) de uma previsão do tempo com base no significado básico de spell como 'magia', estabelecendo uma associação ao domínio BRUXAS. (CAMERON, 1999, p. 109).

Voltando para a questão do experto e do leigo, Charteris-Black e Ennis se perguntam se, para a comunidade de especuladores de bolsa, o uso de palavras como fall e rise ainda apresentam metáforas. (CHARTERIS-BLACK; ENNIS, 2001, p. 254) De modo similar, Giora (2003) coloca em questão a metaforicidade de expressões como window e mouse para especialistas em computadores, cujo acesso online aos significados dessas palavras pode ter sido influenciado pela habitualização do seu uso. Sendo assim, tais significados salientes são ativados primeiro em certas comunidades discursivas. 


\section{Abordagens pragmáticas e interacionais}

Embora, já em 1999, Gibbs reivindicasse estudos que não continuassem localizando metáforas "in the head", mas em sistemas dinâmicos de acoplamento estrutural, "which model how people interact with the world, including different linguistic environments" (GIBBS, 1999, p. 152), é só aproximadamente dez anos depois que ele começa a se dedicar mais aos objetivos das ações dos participantes envolvidos na comunicação. Assim, Tendhal e Gibbs (2008) mostram como as perspectivas da TCM e da Teoria da Relevância de Sperber e Wilson são complementares, uma vez que os últimos representam uma linha cognitiva dentro da pragmática. Na visão de Sperber e Wilson (2008), a metáfora apenas apresenta uma de várias formas da assim chamada loose talk, por sua vez entendida como prática cotidiana da fala cheia de vaguezas. Sendo assim, cabe ao ouvinte construir um significado contextual ao aplicar estratégias interpretativas baseadas no Princípio da Relevância, e ao aplicar seu conhecimento contextual à enunciação dada. Os autores (SPERBER; WILSON, 2002, p. 319) dão um exemplo:

Peter: Can we trust John to do as we tell him and defend the interests of the Linguistics department in the University Council?

Mary: John is a soldier! (SPERBER; WILSON, 2002, p. 319).

Ora, pode-se entender o termo soldado em vários sentidos: (a) John está consciente dos seus deveres, (b) John está à disposição para seguir ordens, (c) John não questiona autoridades, (d) John identifica-se com os objetivos do seu grupo, (e) John é um patriota e pode-se contar com ele, (f) John recebe o salário de um soldado e (g) John é membro do exército. Todavia, através do esquema conhecido apresentado por Peter (confiar, defendendo, interesses), Mary pode entender diretamente o que Peter quer dizer. Tais metáforas representam um fenômeno onipresente na fala cotidiana. Em oposição a outras teorias do campo pragmático, Sperber e Wilson não diferenciam entre modos distintos de compreensão no caso da metáfora em comparação aos demais meios linguísticos, uma vez que cada significado puro de uma frase continua sendo subdeterminado. Nesse sentido, a teoria de Sperber e Wilson, de fato, pode ser vista como compatível e complementar à TCM, pois se dedica ao processo inferencial, aspecto descuidado por Lakoff e 
Johnson. Não obstante, há divergências entre as duas linhas de estudo com relação a definições básicas, como os próprios autores (SPERBER; WILSON, 2008, p. 84) destacam: enquanto os linguistas cognitivos veem a metáfora como fenômeno da língua, constitutivo para a cognição humana, o foco de Spencer e Wilson está na perspectiva comunicativa dos participantes, entendendo a metáfora como "emerging in the process of verbal communication". Nesse ponto, concordamos com Tendhal e Gibbs, para os quais Sperber e Wilson introduzem um aspecto fundamental na discussão. Apesar da perspectiva de Sperber e Wilson também ter suas falhas por se limitar a uma abordagem modular, racionalista, egológica e modelada por uma visão instrumental, voltada apenas para a máxima da relevância, seu lucro está no destaque do caráter complexo e inferencial do processo da compreensão. Com isso, Sperber e Wilson conseguem superar as abordagens intencionalistas de Searle (1995) e Grice (1975), nas quais ambos excluem o lado do ouvinte. ${ }^{5}$ Um ponto decisivo de congruência entre as duas linhas de pesquisa está no caráter ubiquitário da metáfora, que os respectivos autores proclamam. Outro aspecto complementar, a nosso ver, está na introdução implícita das perspectivas comunicativas e extracomunicativas, pois Sperber e Wilson assinalam que, na visão do falante e do ouvinte, não importa a categorização de uma expressão como metafórica, "communicative intentions - like those of all speakers - are about content and propositional attitude, not rhetorical classification". (SPERBER; WILSON, 2008, p. 97). Com isso, a noção da metáfora torna-se um construto do (auto-)observador linguisticamene competente.

Dentro de um quadro de uma 'gramática comunicativa da ação linguística', Beckmann (2001) descreve metáforas como parte de estruturas complexas de ação, entendendo o caminho da metáfora inovativa e criativa à sua lexicalização como guiado por regras e variação. Dirigindo sua atenção ao ouvinte, ela parte de suposição semelhante à de Sperber e Wilson, de que o ouvinte, por seu encaixamento em uma situação comunicativa específica e por ter seu estoque de conhecimento voltado para certos 'padrões de procedimento', per se pressupõe um sentido, de modo que a interpretação de uma expressão é canalizada pelas respectivas

5 Grice (1975) distingue entre significado da sentença e significado do enunciado, de modo que a metáfora é vista como violação das Máximas da Conversação. De modo similar, na teoria da reinterpretação segundo Searle (1993), a compreensão da metáfora passa por um processo de dois passos, no qual o ouvinte (1) deriva uma interpretação literal (2) percebe uma anomalia e, como consequência, só agora tenta aplicar uma interpretação metafórica. Ambos veem atos de fala como ações individuais e não sociais, uma vez que a diferença entre os dois significados apoia a suposição de uma diferença entre competência e performance. 
pressuposições e implicações. A classificação de 'settings comunicativos' distintos possibilita uma observação de fases diferentes do uso da língua metafórica: por exemplo, anúncios de procura de parceiros para relacionamentos são muitas vezes dominados por uma analogia central. As pessoas, muitas vezes, costumam se apresentar como animais ou objetos desejados, como, por exemplo, carros. Sendo assim, a recepção já é preparada pelo quadro textual: o leitor espera um anúncio de procura de parceiros para relacionamentos, de modo que segmentos aliados ao padrão textual como o domínio 'carro’ já são entendidos perante esse horizonte de expectativa. Pela característica semelhante da ação em si, a descrição do produto (carro) do domínio-fonte já é comparável àquela do casamento. No nível funcional, tal analogia permite um distanciamento: o ofertante pode se apresentar sem correr risco de perder a face, o que resolve problemas comunicativos por expor características pessoais sem nomear explicitamente as exigências altas e a oferta baixa. (BECKMANN, 2001, p. 121-124).

Em oposição à convicção da maioria dos representantes da Linguística Cognitiva, em um estudo até hoje único, Hülzer-Vogt (1991) não indaga a predominância da função estruturadora de discurso e criadora de compreensão da metáfora, mas traz à tona conflitos e mal-entendidos de comunicação causados por metáforas. Com isso, a pergunta tradicional pela convencionalidade da metáfora é substituída pelos trabalhos interpretativos dos usuários da língua em uma situação conversacional concreta. Mal-entendidos causados por metáforas acontecem quando uma metáfora é entendida literalmente, quando sua função não é reconhecida ou quando ela é julgada como inadequada. (HÜLZER-VOGT, 1991, p. 360).

Em um estudo-piloto, Hülzer-Vogt descobre que o suposto entendimento recíproco de uma metáfora, muitas vezes, é apenas superficial. (HÜLZER-VOGT, 1991, p. 101-106) Perguntado retrospectivamente pelo sentido da metáfora utilizada durante uma conversação gravada, as explicações do falante e do ouvinte divergiram em alto grau. Hülzer-Vogt conclui que não se pode simplesmente postular uma compreensão automática e desligada do contexto no caso de metáforas 'convencionais'. Tal resultado incitou uma pesquisa com base em encontros regulares entre idosos e estudantes em que se discutem temas políticos, revelando conflitos e mal-entendidos causados por um entendimento divergente das metáforas utilizadas. Por exemplo, em uma discussão, um participante fala sobre o amor, descrevendo-o em conformidade com um artigo jornalístico intitulado Amor 
é falta de espaço. Uma participante não consegue seguir a estrutura argumentativa do falante e quer saber de onde, então, vem essa falta de espaço. Outro participante explica para ela que se trata da ideia do 'espaço' como 'oportunidade', o que já ilustra, semelhantemente ao estudo de Zanotto e Palma (2008), uma interpretação em direção à metonímia, uma vez que o interlocutor estabelece uma conexão entre causa (falta de espaço) e consequência (falta de oportunidade). O destinatário original da pergunta recorre a essa proposta para voltar para o seu campo original, respondendo: “... pois nem cada homem tem a oportunidade de estar em todo lugar e conhecer todas as pessoas potenciais [...] $\mathrm{Na}$ vida inteira, a gente se encontra em um [...] espaço pequeno comparado ao espaço, teoricamente imaginável, em que se poderia mover...” (HÜLZER-VOGT, 1991, p. 360-367). É só essa explicitação do problema ligado ao entendimento da metáfora que contribui para uma compreensão verdadeira dela. Convém salientar que, concomitantemente, a análise de todas as conversações traz à luz que, na fala autêntica, normalmente não há pistas de contextualização explícitas como estratégia para guiar o interlocutor, o que, para Hülzer-Vogt, evidencia que metáforas, geralmente, são utilizadas inconscientemente de modo que não se vê a necessidade de 'prepará-las' para o outro. (HÜLZER-VOGT, 1991, p. 233) Por conseguinte, não supreende que as estratégias mais utilizadas no corpus foram a paráfrase, a caracterização da fala como correção e a exclusão linguística, ergo, primeiramente meios da condução retrospectiva da atenção. Resumindo, Hülzer-Vogt frisa que a metáfora, em oposição às vantagens da transparência, virtualidade e eficiência, devido a sua elipticidade, ao mesmo tempo abre espaço para a ambiguidade do significado e, com isso, para problemas na comunicação. Tais conflitos podem ser explicitados, porém, na grande maioria das situações, continuam escondidos.

$\mathrm{O}$ estudo de Hülzer-Vogt revela a falibilidade da metáfora, aspecto frequentemente descuidado em outras pesquisas pelo fato de que muitos estudos partem ou de situações comunicativas idealizadas ou apenas focalizam um corte pequeno de um evento comunicativo mais complexo, deixando de fora o(s) interlocutor(es) e seu trabalho interpretativo. É certo que metáforas podem tornar as intenções de um falante mais transparentes, contudo, por outro lado, elas sempre apenas selecionam certos aspectos do domínio-alvo, deixando em aberto qual a analogia exata relevante para a construção do significado no nível

6 “... weil nicht jeder Mensch die Gelegenheit hat, überall zu sein und alle Menschen kennenzulernen, die in Frage kämen [...] Man befindet sich eh Zeit seines Lebens in einem [... kleinen Raum, gemessen an dem theoretisch denkbaren Raum, in dem man sich bewegen könnte..." 
cognitivo, o que causa elipticidade e abre o caminho para uma pluralidade de significados. (HÜLZER-VOGT, 1991, p. 370). Outro ponto decisivo para nossa questão é que Hülzer-Vogt revela que as características da fala para especificar e desambiguar uma metáfora são introduzidas durante a conversação primeiramente de modo retrospectivo. Além disso, no campo metodológico, a autora trabalha com entrevistas retrospectivas. Sendo assim, ela já considera o fato de que, por um lado, os próprios participantes da comunicação oscilam constantemente entre uma atitude comunicativa e extracomunicativa e, por outro lado, o pesquisador sempre deveria indicar qual o modus em que ele procede nas suas interpretações.

Um impulso elucidativo face à questão da compreensão vem do campo dos estudos da língua estrangeira: o estudo-piloto de Littlemore (2003) trata de motivos culturais para o mal-entendio de uma metáfora e sua relevância para o ensino e aprendizagem da língua estrangeira. Intercambistas bengaleses, em uma universidade britânica, foram perguntados por sua compreensão e avaliação de certas metáforas utilizadas pelos professores. As metáforas foram escolhidas conforme o sistema de valores de Hofstede (1983) que, por sua vez, localiza culturas em quatro escalas: 'Resistência à Incerteza', 'Distância do Poder', 'Individualismo/Coletivismo' e 'Masculinidade/Feminilidade'. Os resultados revelaram que os estudantes bengaleses tenderam a entender apenas aquelas metáforas que estão de acordo com seu sistema de valores. Destarte, por exemplo, tiveram problemas com a compreensão da expressão freeing up external trade e sua avaliação positiva inerente, uma vez que up não foi avaliado positivamente, porque na cultura de origem, protecionismo é avaliado mais positivamente do que liberalismo mercantil. Mesmo quando os estudantes não tiveram problemas com relação à interpretação do conteúdo da metáfora, muitas vezes, houve uma reinterpretação em sintonia com o próprio quadro cultural, como na expressão we have these top-down, bottom-up forms of assessment, expressão que é avaliada negativamente pelo professor inglês, mas positivamente pelos intercambistas, pois em Bangladesch, hierarquias são aceitas e não questionadas. Para Littlemore, uma conclusão que apoia a Teoria da Metáfora Conceitual é que de fato não se pode simplesmente postular a existência de 'metáforas mortas', uma vez que, especialmente para aprendizes da língua estrangeira, tais metáforas são mais transparentes do que para os falantes nativos. 


\section{Considerações Finais}

Os trabalhos psicolinguísticos de Gibbs marcam o começo de uma integração do interlocutor e seu processamento metafórico nas pesquisas cognitivas da metáfora, introduzindo a questão-chave de até que ponto a etiquetação 'metáfora' de fato assume um papel relevante no processo atual da compreensão. Embora essa fundamentação de um campo de pesquisa específica apresente um lucro indispensável, cabe perguntar se os resultados obtidos realmente conseguem aproximar o pesquisador da função da metáfora na comunicação real, pois as frases com que se opera nos experimentos foram recortadas do seu contexto de uso e de seus objetivos na ação. Com isso, o entrelaçamento entre o subjetivo e o social continua no escuro. No entanto, especialmente pelos protocolos do Thinking Aloud, ${ }^{7}$ Gibbs e também Steen focalizam, pela primeria vez, uma documentação microscópica dos processos reflexivos e autoreflexivos que ocorrem durante a construção do significado, acrescentando uma metodologia inovativa ao campo da TCM. Não obstante, tanto Gibbs como Steen reivindicam mais do que conseguem cumprir. É surpreendente que Gibbs (1999) defenda tirar a "metaphor out of our heads and putting it into the cultural world" e Steen proponha uma recordação de Gumperz e Hymes, mas os dois não vão além do texto escrito, de modo que conversações ou até formas não verbais de interações ficam fora da base empírica deles. Com isso, eles perdem um aspecto importante, pois é justamente Gumperz (1982) quem ilustrou precisamente como pistas da contextualização não verbais e paraverbais devem ser integradas na análise da conversação, embora Gumperz não tenha observado a metáfora como fenômeno específico. Contudo, o artigo de Tendhal e Gibbs mostra uma direção promissora ao integrar os processos inferenciais a um estoque de conhecimento e de atitudes compartilhadas por uma certa comunidade de fala. É este o caminho que também os estudos no campo da análise do discurso de Cameron, Giora e Charteris-Black e Ennis escolheram, por olhar por trás das palavras, tematizando a situação comunicativa como gênero específico ou a constelação e o status dos participantes.

Opondo-se ao otimismo face à eficiência da metáfora como meio comunicativo, Hülzer-Vogt dá uma olhada profunda na sua vagueza e seu potencial para mal-

7 Porém, o método tem um ponto fraco: o paradoxo está no fato de que o pensar alto apenas pode articular o que já foi acessado pela consciência, embora os processos da compreensão geralmente vão além disso. 
entendidos e problemas de comunicação, o que marca um campo inovativo dentro dos estudos sobre a metáfora cognitiva e, ao mesmo tempo, um campo ainda a ser explorado muito mais no futuro. Dentro desse cenário, os trabalhos de Littlemore demonstram par excellence como os estudos sobre a língua estrangeira podem contribuir com resultados válidos para a Semântica Cognitiva. Nessa perspectiva, metáforas podem representar um obstáculo no processo da compreensão, devido a sua motivação cultural. Aqui, vem à luz como a metáfora rapidamente torna a comunicação falível, assim que ela sai do seu meio habitual.

Em nossas interações cotidianas, a metáfora faz parte da enunciação de um falante como instrução para o ouvinte realizar certos atos experienciais. Se o ouvinte de fato compreende a metáfora da forma intencionada ou não representa uma questão complexa, que depende da interação entre rotinas de interpretação e focalizações contextuais com base nas hipóteses individuais sobre o mundo e sobre a situação comunicativa em andamento. Por muito tempo, a complexidade do processo da compreensão da metáfora e a construção ativa do significado por um interlocutor foram aspectos marginalizados nos estudos sobre a metáfora conceitual, também devido à exclusão antagonista de questões localizadas habitualmente no campo da retórica. Entender o processo da comunicação como coordenação de ações que envolvem os dois lados do interlocutor - seu papel como falante $e$ ouvinte - poderia indicar um caminho para superar tais limitações artificiais. 


\title{
The underrated role of the interlocutor in the cog- nitive approach of metaphor
}

\begin{abstract}
One of the most salient critics concerning the Conceptual Metaphor Theory is that of Lakoff and Johnson (2003, 1999). It parts from an idealized constellation of interlocutors, implying that metaphor comprehension is realized by the mere activation of conceptual metaphors entrenched in the mind of the participants (GIBBS, 2007). The article deals with approaches that direct their attention to the hearer as having an active part in the communication process, co-constructing the particular meaning of a metaphoric expression in dependence of the pragmatic, social and cultural context in which the interactants are engaged. The central question is to which extent the presently existing studies manage the necessary reintegration of the holistic communication process. Therefore, we distinguish between research studies in the fields of psycholinguistics, textual and discourse analysis as well as interactional pragmatics.
\end{abstract}

Keywords: Conceptual Metaphor Theory. Interlocutor. Comprehension. Communication. Interaction.

\section{Referências}

BECKMANN, Susanne. Die Grammatik der Metapher. Eine gebrauchstheoretische Untersuchung des metaphorischen Sprechens. Tübingen: Max Niemeyer Verlag, 2001.

BÜHLER, Karl. Sprachtheorie: die Darstellungsfunktion der Sprache. Stuttgart: Fischer, 1982. Original publicado em 1934.

CAMERON, Lynne. Identifying and describing metaphor in spoken discourse data. In: CAMERON, Lynne; LOW, Graham (Ed.). Researching and applying metaphor. Cambridge: Cambridge University Press, 1999. p. 105-132.

CHARTERIS-BLACK, Jonathan; ENNIS, Timothy. A comparative study of metaphor in Spanish and English financial reporting. English for specific purposes, v. 20, p. 249-266, 2001. 
GIBBS, Raymond W. Jr. The poetics of mind: Figurative thought, language, and understanding. Cambridge: Cambridge University Press, 1994.

GIBBS, Raymond W. Jr. Taking metaphor out of our heads and putting it into the cultural world. In: GIBBS, Raymond W. Jr.; STEEN, Gerard J. Metaphor in cognitive linguistics. Amsterdam, Philadelphia: John Benjamins Publishing Company, 1999. p. 145-166.

GIBBS, Raymond W. Jr. Why Cognitive Linguists Should Care More About Empirical Methods. In: EVANS, Vyvyan; BERGEN, Benjamin; ZINKEN, Jörg (Ed.). The cognitive linguistics reader. London: Equinox Publishing, 2007. p. 40-56.

GIBBS, Raymond W. Jr.; O'BRIAN, Jennifer. Idioms and mental imagery: The metaphorical motivation for idiomatic meaning. Cognition, 36, 1990. p. 35-64.

GIORA, Rachel. On our mind: Salience, context, and figurative language. New York: Oxford University Press, 2003.

GRICE, Herbert P. Logic and conversation. In: COLE, Peter; MORGAN, Jery L. Syntax and semantics. New York: Academic Press, 1975. p. 41-58.

GUMPERZ, John. Discourse strategies. Cambridge: Cambridge University Press, 1982.

HEIDEGGER, Martin. Sein und Zeit. Tübingen: Niemeyer, 1957. Original publicado em 1927.

HOFFMAN, Robert R.; KEMPER, Susan. What could reaction-time studies be telling us about metaphor comprehension? Metaphor and symbolic activity, v. 2, p. 149-186, 1987.

HOFSTEDE, Geert. National Culture in Four Dimensions. A Research Based Theory of Cultural Differences among Nations. International studies of management and organization, v. 13, p. 46-74, 1983.

HÜLZER-VOGT, Heike. Kippfigur Metapher - metaphernbedingte Kommunikationskonflikte in Gesprächen. Ein Beitrag zur empirischen Kommunikationsforschung. Band 1: Gesprächsanalyse. Münster: Nodus Publikationen, 1991.

HUSSERL, Edmund. Logische Untersuchungen. Band 2, Zweiter Teil: Elemente einer phänomenologischen Aufklärung der Erkenntnis. Halle: Max Niemeyer, 1921. Original publicado em 1901. 
LAKOFF, George; JOHNSON, Mark. Metaphors we live by. Chicago: The University of Chicago Press, 2003. Original publicado em 1980.

LAKOFF, George; JOHNSON, Mark. Philosophy in the flesh. The Embodied Mind and its Challenge to Western Thought. New York: Basic Books, 1999.

LITTLEMORE, Jeannette. The Effect of Cultural Background on Metaphor Interpretation. Metaphor and symbol, v. 18, n. 4, p. 273-288, 2003.

NAYAK, Nandini P.; GIBBS, Raymond W. Jr. Conceptual knowledge in the interpretation of idioms. Journal of Experimental Psychology: general, v. 119, p. 315-330, 1990.

SCHMITZ, Heinrich Walter. Über kommunikative und extrakommunikative Betrachtungsweisen. In: KRALLMANN, Dieter; SCHMITZ, Heinrich Walter. Perspektiven einer Kommunikationswissenschaft. Münster: Nodus Publikationen, 1998. p. 315-326.

SCHMITZ, Heinrich Walter. Die Einheit des kommunikativen Ereignisses. In: RICHTER, Helmut; SCHMITZ, Heinrich Walter. Kommunikation - ein Schlüsselbegriff der Humanwissenschaften? Münster: Nodus Publikationen, 2003. p. 197-206.

SCHRÖDER, Ulrike. Trinta Anos da Teoria Conceptual da Metáfora: uma Retrospectiva Crítica. Cadernos de Estudos Linguísticos, v. 53, p. 59-71, 2011. SCHRÖDER, Ulrike . Kommunikationstheoretische Fragestellungen in der kognitiven Metaphernforschung. Eine Betrachtung von ihren Anfängen bis zur Gegenwart. Tübingen: Gunter Narr Verlag, 2012.

SEARLE, John R. Metaphor. In: ORTONY, Andrew. Metaphor and thought. Cambridge: Cambridge University Press, 1993. Original publicado em 1979.

SPERBER, Dan; WILSON, Deirdre. Pragmatics, modularity, and mind-reading. Mind \& Language, v. 17, p. 3-23, 2002.

SPERBER, Dan; WILSON, Deirdre. A Deflationary Account of Metaphors. In: GIBBS, Raymond W. Jr. The Cambridge handbook of metaphor and thought. Cambridge: Cambridge University Press, 2008. p. 84-105.

STEEN, Gerard J. Understanding metaphor in literature: An empirical approach. London: Longman, 1994.

STEEN, Gerard J. Can discourse properties of metaphor affect metaphor recognition? Journal of Pragmatics, v. 36, p. 1.295-1.313, 2004. 
STEEN, Gerard J. Finding metaphor in grammar and usage. Amsterdam, Philadelphia: John Benjamins, 2007.

TENDHAL, Markus; GIBBS, Raymond W. Jr. Complementary Perspective on Metaphor: Cognitive Linguistics and Relevance Theory. Journal of Pragmatics, v. 40, p. 1.823-1.864, 2008.

UNGEHEUER, Gerold. Kommunikative und extrakommunikative Betrachtungsweisen in der Phonetik. In: UNGEHEUER, Gerold. Sprache und Kommunikation. Herausgegeben von Karin Kolb und Heinrich Walter Schmitz. Münster: Nodus Publikationen, 2004. p. 22-34. Original publicado em 1972.

UNGEHEUER, Gerold. Was heißt ,Verständigung durch Sprechen'? In: UNGEHEUER, Gerold. Kommunikationstheoretische Schriften I: Sprechen, Mitteilen, Verstehen. Herausgegeben von Johann G. Juchem. Aachen: Rader Publikationen, 1987. p. 34-69.

WEGENER, Philipp. Untersuchungen über die Grundfragen des Sprachlebens. Wiederherausgegeben von Konrad Koerner. Amsterdam: John Benjamins, 1991. Original publicado em 1885.

ZANOTTO, Mara Sophia; PALMA, Dieli Vesaro. Opening Pandora's box: Multiple readings of 'a metaphor'. In: ZANOTTO, Mara Sophia; CAMERON, Lynne; CAVALCANTI, Marilda C. Confronting metaphor in use. An applied linguistic approach. Amsterdam, Philadelphia: John Benjamins, 2008. p. 11-43. 
